\title{
Toward Flipped Learning on Mobile Multimedia Design for CSIE Student at UCH
}

\author{
Fu-Tung Wang*, Ta-Wei Lin, Hui-Feng Tsai \\ Department of Computer Science and Information Engineering, Chien Hsin University of Science and \\ Technology, Taoyuan, Taiwan.
}

* Corresponding author. Tel.: +886-3-4581196; email: futung@uch.edu.tw

Manuscript submitted September 1, 2016; accepted March 1, 2017.

doi: 10.17706/ijeeee.2017.7.1.51-58

\begin{abstract}
This paper presents an experience of a flipped Learning on mobile multimedia design courses within the Department of Computer Science \& Information Engineering (CSIE) at Chien Hsin University of Science and Technology (UCH), Taiwan. With responding to the major trends and challenges posed by current teaching field, student-centralized learning was developed to promote students employability and competitiveness. Project - as a crucial activity was assigned and traced to make sure learning effect. It was found that the teaching support tools are important elements for flipped learning and we have also discovered that students can quickly and effectively apply Internet resources themselves. They could apply cloud services and develop mobile phone application easily.
\end{abstract}

Key words: Flipped learning, distance learning, seamless learning, blended learning.

\section{Introduction}

Currently, the education direction has been setup as more diversity and more innovative to raise the motivation of undergraduate student [1]-[9]. Along the rapid growth of the Internet, online learning has been becoming common in higher education. It is one of the most used Internet-based technologies as a complementary method to face-to-face teaching or as a major means for communication in distance learning. Reported advantages of online discussions includes promoting creative thought in the discussion, encouraging active learning, and supporting collaborative knowledge construction [6], [7].

Students usually manage investing less time and efforts to get the credit. They appreciate to learn at any place and any time flexibly. Therefore, many researchers focused on learning theory and concept evolution to address the teaching-learning field challenge. Flipped learning concept which more emphasizes on student-centered learning activities has get more attention [1]-[4]. It allows students having more opportunities to shape their goal, coordinate and synchronize their learning tempo, pop their problems and get help.

Besides dealing with the education issues and tech supporting improvement, the teaching-learning field has another challenge for Taiwan vocational college teacher because of the low birth rate [5]. Most young vocational students need more motivation and more positive outcome to encourage their learning. Responding to above mentioned situation, a mobile multimedia courses which designed in flipped learning was proposed and performed by CSIE at UCH. In this experiment, blended learning skill was adopted to fulfill the need while students learning by themselves. It was develop to exploit online resources in class-based learning to promote students professional skill and competitiveness for vocational college 
students. The methodology was combined with practice learning by student self-learning and convey the programming skill by face to face teaching.

This paper reports an experience of this course performing and presents the outcome which analyzed by query feedback data. The remainder of this paper is presented as follows: Section 2 describes the related learning concepts. Section 3 describes the courses practices. Section 4 presents the learning effectiveness. Finally, section 5 contains the conclusions.

\section{Related Learning Concepts}

Flipped learning helps teachers move toward a more student-centered approach from direct instructing approach [1]-[4]. It is in connection with student need and emphasizes about how to use more efficiently in-class time. The teacher interacting with students is more personalized with guiding instead of lecturing. Students are always asked to do project in home and present, discuss and solve questions with teachers and classmates in class. It is a form of blended learning in which students learn content not only in classroom but also on Internet by watching video lectures or studying teaching material at home.

In e-Learning or classroom-Learning, we need more efficiency and focus on teaching and learning activities . By Internet technology supporting, learners are given the opportunity to collaborate and interact within their peers in new ways. The physical world skill also can be enhanced through the using of cloud technologies. Learners would be encouraged to enlarge their learning boundary [8], [9].

The blended teaching utilize Internet resources to improve teaching effectiveness and two issues have been addressed. The first one is how to determine the relationship between teaching objectives and teaching requirements. The second is how to adopt the personalized learning? Two modes are suggested for addressing the personalized learning [2]-[4]. The first one is that the learning style and learning process are controlled, where teaching goals and teaching requirements are consistently maintained. The second mode is that students can plan the learning process according to their preferences. The various features between the personalized learning goals and the teaching goals make students have more chances to participate and get the feedback and express themselves in the blended classroom.

Seamless learning refers to the seamless integration of the learning experiences across various dimensions including formal and informal learning contexts, individual and group learning, and physical world and cyberspace. A ubiquitous learning environment is a pervasive and persistent setting allowing students to access learning materials flexibly and seamlessly in any location at any time, both from the physical environment and from the Internet [1].

With the increasing of processing capacity of mobile terminals and the popularization of cloud computing application, it will be expected the flipped learning could lead an evolution by adopting learning concepts.

\section{Courses Practices}

Course design has to reasonably design with sound knowledge foundation and shifted to student centered. In this study, practice-oriented lessons are used to transfer professional skills to students covering the depth and broadness. Students are expected to complete a mobile application after lesson activity and the course is described as follows.

\subsection{Objective}

Toward to implementing flipped learning concept, we integrated two courses for first semester 2015 in undergraduate CSIE programs at UCH. Designed courses intended to reflect the evolution of learning concept and guide students to abide with suitable learning supporting. Under these goals, three phases: face to face lecturing, on-line learning supporting and problem answering were developed to get across mobile multimedia design course and mobile multimedia design practice course. 
1) CS0252 Mobile Multimedia Design: this course Objective is to understand basic concept of multimedia design on mobile device and learn the programming ability on mobile device. The goal is to implement a multimedia mobile application with forced multimedia designing, including the photo image, sound and video. After the completion of the course, leaners can setup the basic programming ability and can communicate with other programmers.

2) CS0253 Mobile Multimedia Design Practice: this course objective is to learn the programming skill of AppInventor by carrying out the assignments of mobile applications. This course focus on the designing concept and develop a mobile application. It is expected that the theory and practice ability of multimedia App could be built and the project should be carried out in this semester.

\subsection{Teaching Resources}

Mobile multimedia design curriculum is characterized by various content, broad knowledge, and strong program skill. It is difficult to cover everything in the limited teaching time. Therefore, the goal is set as that students can choose and implement their target project which matching their familiar fields or according to their interests. Therefore, resources development is very important in order to offering all the students need.

The cloud environment has been used to support the blended teaching of mobile multimedia design course. Teacher uses e-learning platform to teach in class, set assignments, discuss or explain the concepts. More teaching resources are offered as compared to traditional classroom teaching, for example, videos, pictures, e-books and other Internet resources. Students use Internet to learn, discuss, and submit assignments. Teachers and students were encouraged to make full use of tablets, smart phones and PCs to upload materials or learn resources through the Internet. In this case, these resources include example cases, lecture for difficult application, document template, such as project progress sheet, test use case or test plan, etc.

Finally, the teaching modules were setup and the example were online using. The students were expected to get acclimated to the Internet environment and dedicated to self-learning on developing a mobile App. The teacher was primarily responsible for example learning, problem consulting and outcome evaluating.

\subsection{Teaching Activities}

Toward to flipped learning, the time on face to face lecturing are reduced in "mobile multimedia design" course and mile stone checking and problem solving are assigned in "mobile multimedia design practice" course. All of them were taught in classroom. The lecturing phases teach students to learning concept by example excises on mobile multimedia profession. The class teaching process would essentially cover example practicing, class/home assignment, discussion and evaluation.

\subsubsection{Teaching}

The first phase began with an initial example practicing while the teacher briefing the App goal and mobile function usage. The application develop cloud platform - AppInventor was induced. The incremental method which function are introduced in proper sequence. Therefore, students could construct incrementally an application step by step. Then an assignment would be released to students to complete. After a pre training in classroom, the participants were asked to complete a project by using the rest time.

\subsubsection{Assignment}

There are two types of assignments: Compulsory assignments for all students can be used to prove as their programming ability. Elective assignments for students chooses according to their own preferences and ability can be used to evaluate the familiarity. Then students spent all the rest time to plan the final project and develop their application. Students were expected to convey their multimedia experience to program a mobile App. They should complete a tried application and document the activities in scheduled 
period. They were asked to report and present their result at the final class meeting.

\subsubsection{Discussion}

Asynchronous interaction allows teachers or students to leave a message at any time on Internet such as social web site. Special topics are organized for students to discuss such as on demands function design, project idea design, and project management. The discussion is always carried out in class.

\subsubsection{Evaluation}

The comprehensive evaluation can be organized by teachers at the beginning of the term, during the semester and at the end of the term. Appling Google App to record the students learning process and carrying out formal assessment of students learning according to procedural tracking activity. Topical or comprehensive assessment can be carried out any time to test the students understanding. The assessment can be initiated by the students, or organized by the teachers.

The course has a total 36 teaching hours. There are 8 weeks of classroom teaching and 8 weeks of project practice. By introducing the blended learning method, the students would understand the Internet resources and they were asked to utilize these resources at home in order to complete their project. Each student was expected to write down a milestone report what they complete which records helped the final mobile application completing as well as insured that they could reveal their problem to teacher when they encountered obstacles immediately.

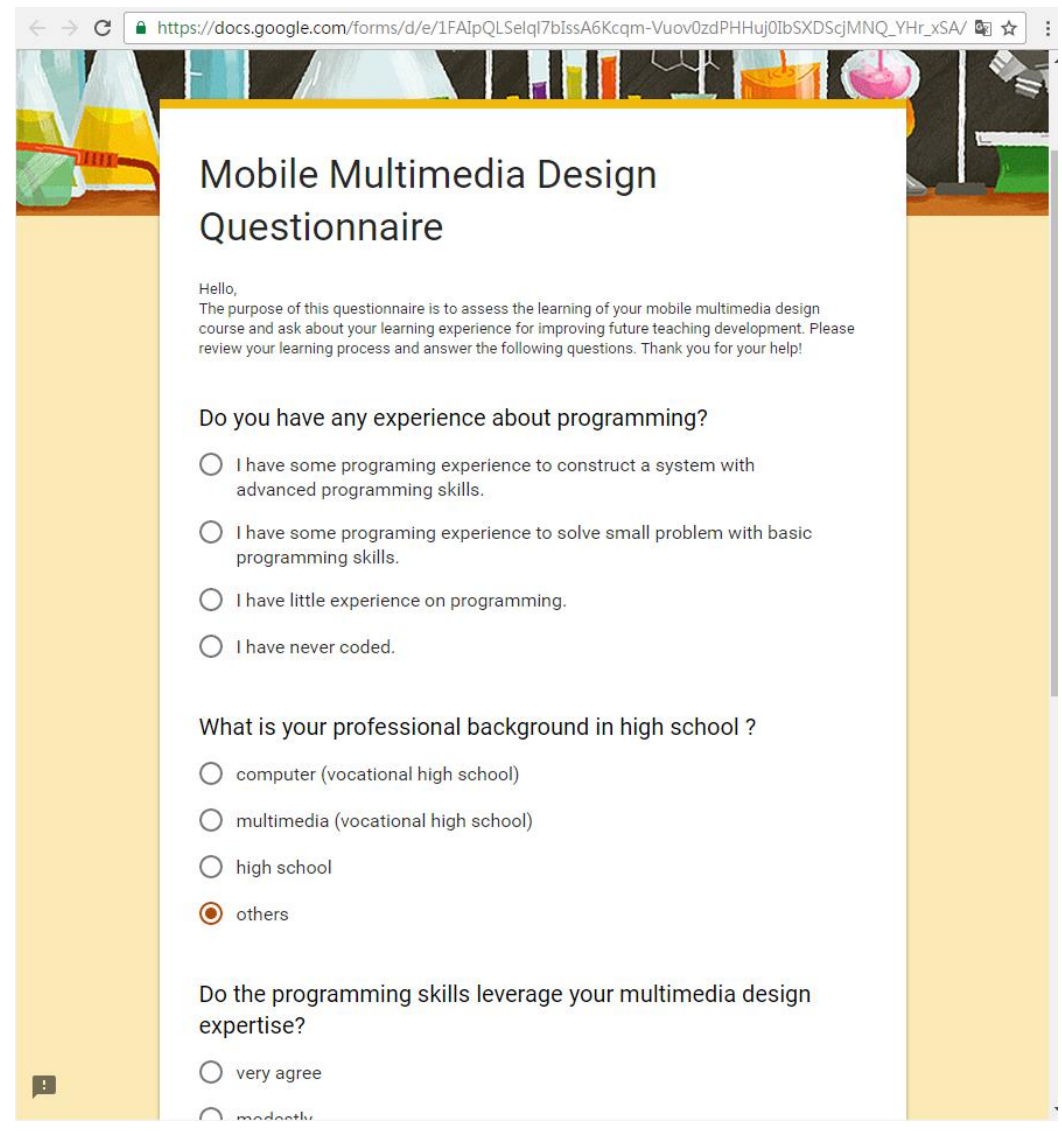

Fig. 1. Screenshot of the questionnaires.

\section{Learning Effectiveness}

After finishing a flipped experiment on Mobile Multimedia Design course, data was collected and analyzed on the teaching effectiveness with considering the blended supporting. We analyzed data from 39 
students (about 80\% respondent rate). The analysis was based on three facets, including student participation, student satisfaction and learning benefits. The screenshot of the questionnaires as shown in Fig. 1.

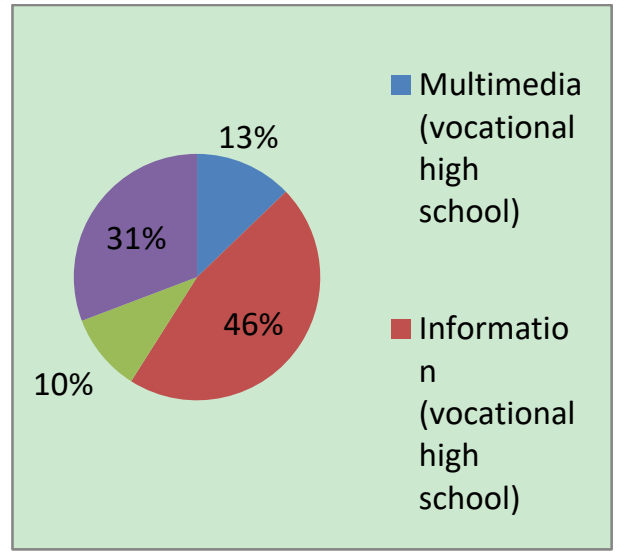

Fig. 2. Learning background investigation.

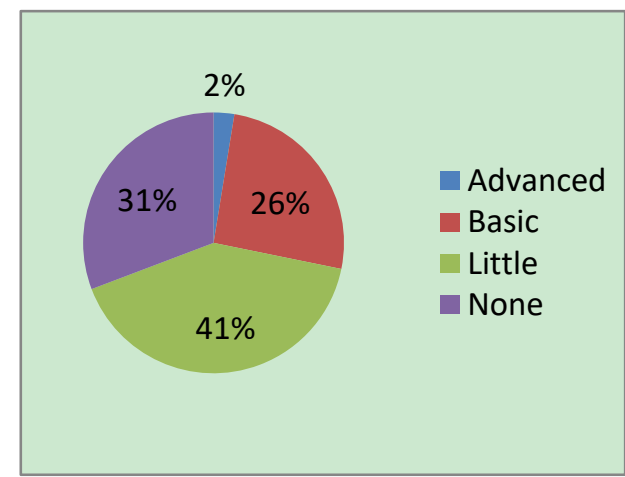

Fig. 3. Programming ability investigation.

From the perspective of student investigation as shown in Fig. 2, there are $46 \%$ student with computer background coming from vocational high school, there are 13\% student with multimedia background, and there are $10 \%$ student coming from high school, and the rest students belong to other technology group in vocational high school. From the perspective of student program experience investigation as shown in Fig. 3, there are $28 \%$ student have ever used programming to solve simple problem and there are $41 \%$ student have ever learned programming skill. However, there are still 31\% student have no experience for programming. It is obvious, the baseline for start-teaching App develop is hard to set. Therefore, how to provide dynamic learning environment for those students is a challenge.

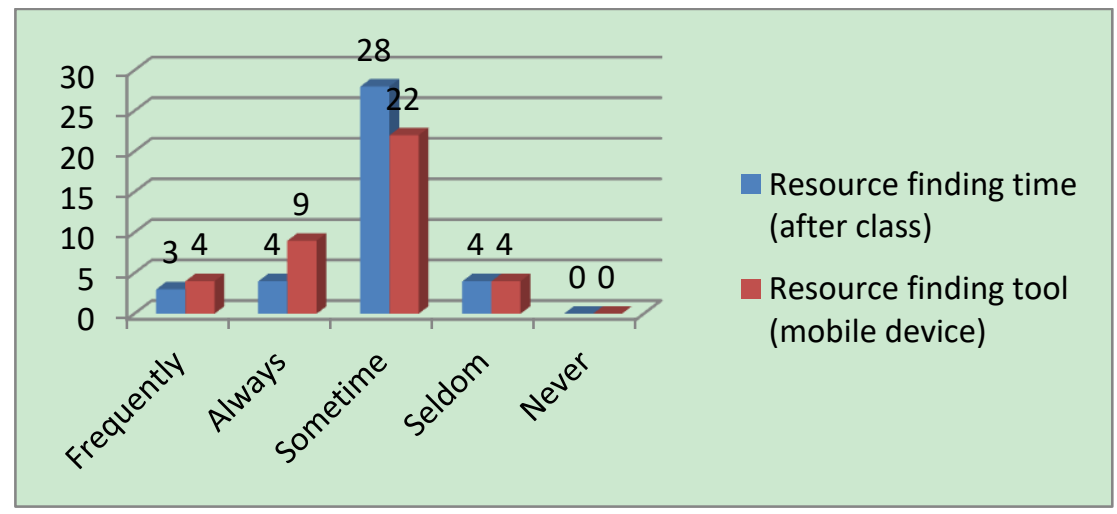

Fig. 4. Learning resource finding time/tool investigation.

The resource finding survey results are shown in Fig. 4. For learning period investigation, the proportion of $72 \%$ students searching resources sometime lead most portion while still the proportion of $10 \%$ students seldom to gain learning resources. This result shows the challenge of how to motivate student to solve problem and build programming capability is real and should be conquered.

Considering where students fetch the learning resources, most of student get lesson from Internet, the rate is $90 \%$. The second resources is come from Internet video and the rate is $64 \%$. It reveals that the Internet resources are favor to students to locate. And $26 \%$ of students get the resources from digital school platform. Only 7 students find help in library. It is obvious that network learning is important resources offering sites as shown in Fig. 5. 




Fig. 5. Learning resource investigation.

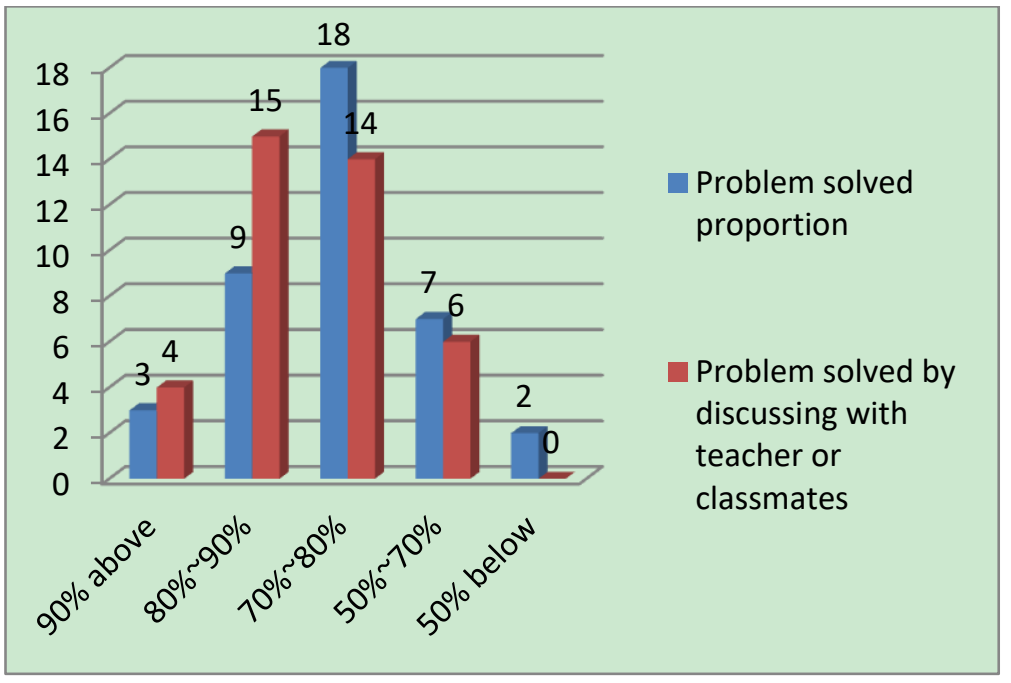

Fig. 6. Learning benefits of problem solving investigation.

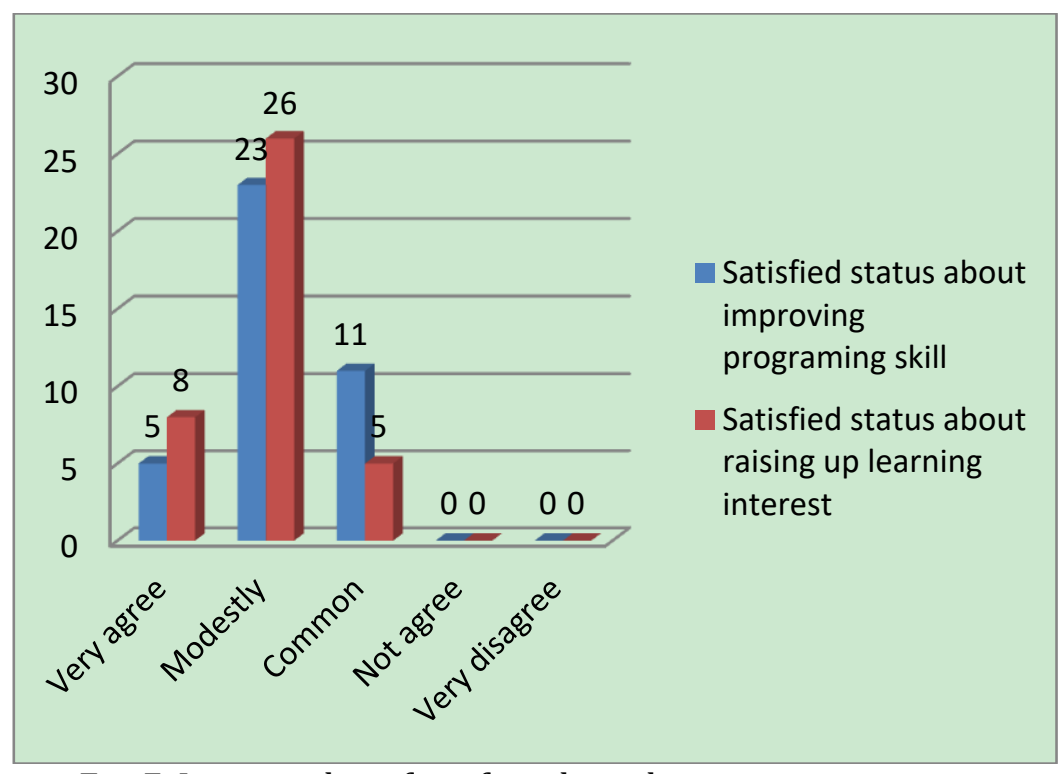

Fig. 7. Learning benefits of teaching design investigation. 
Gains survey exploration and learning benefits are investigated through questionnaires as shown in Fig. 6 and Fig. 7. It is found that half of questions be solved by student-self and most of difficult problems are solved by discussion with teacher or classmates during interactive activity in class. In Fig. 7, it is provided five options, namely, very agree, modestly, common, not agree and very disagree. As can be seen, the number of students that are not satisfied is 0 . It shows that agree with learning interesting level up about $87 \%$ and agree with programming ability level up about $72 \%$. The results promised the blended learning course design are basically satisfied with the attended students on Mobile Multimedia Design Practice course.

\section{Conclusion}

Nowadays, flipped learning is gaining acceptance and being adopted at college to address learning challenge. It was shown that blended teaching approach is useful for teaching Mobile Multimedia Design courses and make flipped learning become true. Student centered activities can promote students motivation and enhanced their multimedia programming capability. Extending the boundaries of the classroom into the home by mobile technology could level up students learning experience. Students have longer learning time, because the time covers both online learning and classroom teaching. Students can interact resources with other teacher or learners on Internet. They gain important skill which they really need by actually operating the cloud program develop platform. Students could upgrade professional potentials on App programming. Finally, they believed that they can be better through student centered learning actions.

\section{References}

[1] Tsai, C.-Y., et al. (2015). Toward a highly interactive model of flipped learning. Lecture Notes in Computer Science, 9167, 173-186.

[2] Cheung, K. S., Lam, J., Lau, N., \& Shim, C. (2010). A paradigm in instructional design to support blended learning. Proceedings of the International Conference on ICT in Teaching and Learning (pp. 271-276).

[3] Li, K., \& Zhao, J. (2004). The principle and application of the blended learning model. E-education Research, 7, $1-6$.

[4] Pang, Y. (2010). Techniques for enhancing blended learning of physical education. Proceedings of the International Conference on Blended Learning (pp. 35-46).

[5] Wang, F.-T., et al. (2015). Work scene learning cooperated with school-based learning - A case study of placement course. Proceedings of the International Symposium on Educational Technology (pp. 153-157).

[6] Mao, G., \& Liu, Q. T. (2015). A case study of online course analysis based on instant messaging tools. Proceedings of the International Symposium on Educational Technology (pp. 8-14).

[7] Kwan, K. N., et al. (2015). The impact of online discussion platform on students' academic performance. Lecture Notes in Computer Science, 9167, 199-208,

[8] Grewal, A., et al. (2005). The e-learning lifecycle and its services: The web services approach. Proceedings of the Second International Conference on eLearning for Knowledge-Based Society, Vol. 8, (pp. 4.1-4.8).

[9] Murari, B. M. (2013). A cloud based architecture for optimal utilization of resources in educational institutions. Proceedings of Machine Intelligence and Research Advancement (pp. 569-573). 


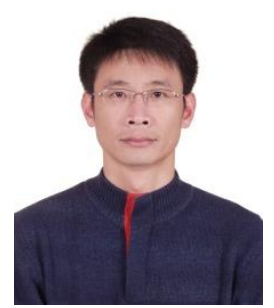

Fu-Tung Wang was born in Ping-Tung, Taiwan, on December 29, 1965. He received the B.S.E.E from Chung Cheng Institute of Technology, Taiwan, R.O.C., in 1988. He received the M.S. and Ph.D. degree from National Central University in 1993 and 2002, respectively. He served in the Information Center of R.O.C. Army from 1993-1998. He was an information operations chief instructor in the Army communication school of R.O.C. Army from 2002 to 2007. He has been an assistant professor in the Department of Information Management at Nanya Institute of Technology from 2007 2008. He is currently an assistant professor in the Department of Computer Science and Information Engineering at Chien Hsin University of Science and Technology since 2008. His research interests include information security, computer network, automatic identification and neural network. 